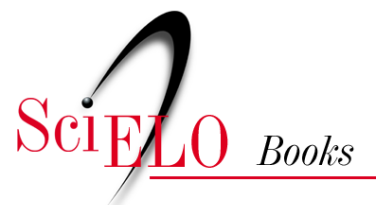

\title{
7 - Povos do campo, memória e Patrimônio biocultural na Defesa dos territórios da América latina
}

\author{
Lia Pinheiro Barbosa
}

\section{SciELO Books / SciELO Livros / SciELO Libros}

BARBOSA, L. P. Povos do campo, memória e Patrimônio biocultural na Defesa dos territórios da América latina. In: OLIVEIRA, G. M. C., and VIEIRA, K. M. A., eds. Patrimônio, povos do campo e memórias: diálogos com a cultura, a arte e a educação [online]. Mossoró: EdUFERSA, 2020, pp. 107-121. ISBN: 978-6587108-09-4. https://doi.org/10.7476/9786587108605.0008.

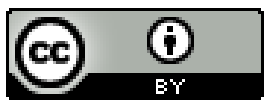

All the contents of this work, except where otherwise noted, is licensed under a Creative Commons Attribution 4.0 International license.

Todo o conteúdo deste trabalho, exceto quando houver ressalva, é publicado sob a licença Creative Commons Atribição 4.0.

Todo el contenido de esta obra, excepto donde se indique lo contrario, está bajo licencia de la licencia Creative Commons Reconocimento 4.0. 


\section{POVOS DO CAMPO, MEMÓRIA E PATRIMÔNIO BIOCULTURAL NA DEFESA DOS TERRITÓRIOS DA AMÉRICA LATINA}

Lia Pinheiro Barbosa

\section{Introdução}

O processo histórico de desenvolvimento do capitalismo em escala global afetou, profundamente, a natureza das relações sociais e de produção em diferentes regiões do mundo. Da acumulação primitiva (MARX, 2011) ao continuum da reprodução ampliada do capital (LUXEMBURGO, 1970), chegamos ao final do século XX com reconfigurações do padrão de acumulação por espoliação (HARVEY, 2004), a intensificação da expropriação territorial, bem como o acirramento na disputa de concepções de desenvolvimento territorial entre o capital transnacional e os diferentes povos do campo, sejam povos originários, camponeses, populações tradicionais, ribeirinhos, quilombolas, pescadores, entre outros.

Pesquisas vinculadas ao campo dos estudos agrários demonstram, sob o prisma do materialismo histórico dialético, que a luta de classes, em nossa história recente, acentua-se nas zonas rurais do sul global (VELTMEYER, 2019; FEDERICI, 2019; BARBOSA, 2016; 2018; OSORIO, 2007). A expansão de um modelo de desenvolvimento agrícola corporativo de grande escala (VAN DER PLOEG, 2008) e uma política econômica baseada nas commodities, notadamente pelo incremento do modelo neoextrativista, evidenciam o interesse de expansão do capital transnacional, sobretudo no território latino-americano. A questão energética tem aprofundado a disputa dos 
territórios para a exploração hídrica, eólica, mineral e da biodiversidade, acentuando os conflitos no campo e um processo de desterritorialização forçada em diferentes países da região.

Frente a esse contexto, a defesa dos territórios e dos comuns revela seu caráter intrínseco à histórica resistência dos povos originários, camponeses e populações tradicionais na América Latina. Diferentes expressões de sua ação política têm incidido no enfrentamento desse novo padrão de acumulação, em especial ao propor e impulsionar projetos políticos alternos baseados em outro paradigma onto-epistêmico do campo (BARBOSA, 2019). No presente capítulo, apresentarei alguns elementos que estruturam a natureza dos projetos políticos articulados por esses sujeitos históricos nos processos de defesa dos territórios e dos comuns na região e sua relação com a memória e o patrimônio biocultural.

Uma premissa fundamental do escrito é a de que persiste, na modernidade, a existência de formas de organização sociocultural não capitalistas baseadas em outras matrizes de pensamento, de racionalidade, que lhes permite adjudicar outras concepções de território que se contrapõem à lógica de desenvolvimento territorial auspiciada pelo capitalismo. Do ponto de vista sociológico, a memória constitui um dispositivo central à preservação de um patrimônio biocultural que, em si, é o âmago da coexistência da humanidade com a natureza.

\section{Do Abya Yala ao capitalismo neoextrativista: paradigmas societários antagônicos}

No âmbito dos estudos sociológicos, à exceção de alguns estudos da teoria marxista, pouco se tem debatido acerca da diversificação do processo evolutivo nos âmbitos biológico e cultural, no sentido de analisar, sociologicamente, a heterogeneidade genética, linguística, cognitiva e cultural que acompanha essa evolução histórica da humanidade, suas configurações e graus de incidência nas formas de organização social e nas maneiras de coexistir não só entre os seres humanos, mas com a natureza e os não humanos.

Ao analisar a centralidade do trabalho na transformação do macaco em homem, Engels (1876) argumenta que a modificação do polegar permitiu o salto ontológico humano, acompanhado do desenvolvimento do cérebro, 
dos sentidos e da linguagem, um processo que seguiu seu curso histórico até culminar no aparecimento da sociedade, estágio, diríamos, superior desse salto ontológico e da firmação da humanidade. Entretanto vale destacar que, embora esta humanidade tenha sofrido processos evolutivos em sua base econômica, não seguiu a tendência de homogeneização das relações de produção e das forças produtivas do norte global analisadas pelo marxismo. Permanece, na história da humanidade, sociedades capitalistas e não capitalistas, estas inscritas em uma ordem sociocultural pluriversa e notadamente presentes no sul global.

$\mathrm{O}$ advento da modernidade, marcado por mudanças consubstanciais no âmbito da vida em sociedade, constituiu o período histórico de recognição da ciência e de consolidação da racionalidade ocidental moderna. Essa racionalidade sentou as bases da acumulação e concentração de riquezas, das transformações de ordem econômica, tecnológica, cognitiva e sociocultural, ao passo que negou, limitou, menosprezou, ou mesmo, destruiu diferentes formas de configurações societárias que existiam (e ainda persistem) graças à permanência de uma memória coletiva que resguardou, por séculos a fio, formas de coabitar o mundo, com o manejo equilibrado dos diferentes bens naturais.

Toledo e Barrera-Basols (2008) denominam a modernidade como uma "época cativa do presente", marcada por uma amnésia dos processos históricos de médio e longo alcance e por uma ideologia do progresso, do desenvolvimento e da modernização industrial intolerantes a toda forma de organização da vida "pré-moderna". A intolerância se nutre da negação da existência de um pensamento ameríndio milenarmente constituído (DUSSEL, 2010), que delineia a natureza das relações intersubjetivas e com a natureza, de caráter heterogêneo, pluriverso e que se contrapõe, por vezes de forma não só antagônica, mas também radical, à racionalidade unilateral, de tendência homogeneizadora, que acompanha a moderna ocidental capitalista eurocentrada (BARBOSA, 2019a).

Há, portanto, uma luta permanente, de caráter histórico, entre paradigmas societários antagônicos, isto é, entre os paradigmas que sustentam as sociedades capitalistas e as não capitalistas. Para a análise em questão, 
demarcada no contexto latino-americano, o paradigma onto-epistêmico que se contrapõe ao paradigma ocidental moderno capitalista data do período pré-hispânico, quando éramos o Abya Yala.

Antes da Conquista, os povos originários que habitavam o continente tinham nomes diferentes para designar os diferentes territórios que compõem o que conhecemos como América: Tawantinsuyo (região da atual Bolívia, Equador e Peru), Anauhuac (região do atual México e Guatemala), Pindorama (nome dado ao Brasil pelo povo Tupi). O povo Kuna ${ }^{26}$ atribuiu o nome de Abya Yala, que em sua língua materna significa "terra que floresce", "terra madura", "terra viva", à região que conhecemos como América (ALBÓ; BARRIOS, 1993). Nesses territórios, dentro de uma ampla gama de variações, existiam civilizações com epistemes e ontologias próprias provenientes de cosmogonias, matrizes linguísticas que lhes proporcionam tecidos conceptuais complexos e um modus vivendi em estreita relação entre a vida humana e a pluralidade de seres vivos e não vivos existentes no cosmos, como o atesta a historiografia pré-hispânica (BARRERA-VÁZQUEZ; RENDÓN, 1963; DE LA GARZA, 2012; BARBOSA, 2019b).

No processo histórico da Conquista, toda a complexidade do pensamento dessas populações foi submetida à violência colonial, ao epistemicídio, tornando-se sociedades de silêncio colonial (CUSICANQUI, 2015). No processo de reprodução ampliada do capital, conforme analisada por Luxemburgo (1970), a reprodução não se limita à relação capital-trabalho em sua fase primitiva, originária, mas vai além ao demandar, como condição sine qua non à reprodução do capital, um continuum histórico, na busca de outros segmentos sociais como força de trabalho barata e de espaços geográficos não capitalistas para o fornecimento de matérias-primas, de novos mercados para a circulação de mercadorias e que sejam passíveis de inversão econômica.

Adverte Luxemburgo (1970) que seria ingênuo esperar que o capitalismo limitara sua reprodução tão somente pela via da produção e do comércio de mercadorias, ou ainda que esperara a que se cumpram todas as etapas de

26 Atualmente localizado na costa caribenha do Panamá, o povo Kuna é originário da Serra Nevada no norte da Colômbia e habitou a região do Golfo de Urabá e das Montanhas Dariénn. 
evolução do modelo econômico analisadas por Marx. Isto porque existiam, paralelas às sociedades capitalistas, aquelas sociedades não capitalistas [ao que Luxemburgo denominava sociedades de economia natural], que representavam um entrave à reprodução desse modelo econômico.

As sociedades de economia natural eram precisamente aquelas que foram submetidas à colonização europeia no século XVI, momento histórico de apropriação violenta dos meios de produção próprios desses países, em condição de colônia, para garantir a integração dessas sociedades ao monopólio integral do capitalismo em escala mundial (LUXEMBURGO, 1970). E uma vez instaurada as relações coloniais, se intensificou a impulsão do extermínio de modos de vida não capitalistas para abrir terreno à reprodução ampliada do capital.

É fundamental frisar que na América Latina, historicamente, a reprodução ampliada do capital se circunscreve no campo por meio da expropriação territorial dos povos originários, do campesinato e demais povos do campo. Nessa nova etapa da acumulação por espoliação, vigente no século XXI, o território torna-se cada vez mais objeto de interesse do capital transnacional, por ser reduto hídrico, mineral, eólico, etc. Entretanto, esse modelo perpetua as contradições e antagonismos inerentes ao capitalismo dependente latino-americano e à natureza da ação monopólica e do capital transnacional vinculados ao neoextrativismo.

Ainda no século XX, Mariátegui (1928), em sua elaboração teórico-analítica em torno de uma concepção do socialismo indo-americano, identificou a existência de elementos germinais, como parte do processo histórico do Peru, ligados à sobrevivência das tradições comunitárias camponesas e indígenas nos contextos do desenvolvimento capitalista, o que lhes conferiu uma especificidade diferente em relação à natureza da contradição capital-trabalho predominante na Europa. Nos umbrais do século XXI emergem lutas emblemáticas em nossa região, algumas delas articuladas à reivindicação teórico-política do Abya Yala pelos povos originários, movimentos camponeses e populações tradicionais, para expressar uma unidade de territorialidade geográfica, sociocultural e política. 
Ao posicionarem-se como sujeitos histórico-políticos, esses diferentes povos do campo reivindicam a memória histórica de sua existência de caráter milenar, ao mesmo tempo em que demarcam outro paradigma ontológico e epistêmico para suas formas de ser, pensar e viver, dos seus sentimentos, das suas palavras, da sua racionalidade e das suas ações políticas, demarcando outro paradigma de pensamento e de construção do conhecimento em estreito vínculo com a defesa da terra, dos seus territórios e dos bens naturais, em um sentido comunal e agroecológico (BARBOSA, 2019a). Vejamos alguns elementos que estruturam sua identidade política e suas interfaces com a consolidação de outro paradigma onto-epistêmico.

\section{Identidade política dos povos do campo}

Herdeiros dessa resistência histórica, os povos originários, camponeses, populações tradicionais, entre outros povos do campo, tecem sua identidade e prática políticas em um processo contínuo de recuperação da memória histórica das lutas ocorridas em outros momentos da resistência latino-americana e caribenha. Portanto, a identidade política destes sujeitos históricos não se limita aos elementos constituintes da esquerda internacional, ou seja, aos princípios que estão na base do comunismo e do socialismo como horizonte político.

Sem necessariamente negá-los ou contradizê-los, os povos originários e camponeses ampliam as referências que lhes dão uma identidade política, demarcando que fazem parte de um movimento forjado em mais de cinco séculos de história. Nesse processo de auto definição de uma identidade política, as organizações populares e os movimentos indígenas e camponeses da América Latina estão agrupados em três categorias, definidas a partir de suas próprias epistemes e que articulam marcos identitários vinculados às suas lutas políticas (BARBOSA; ROSSET, 2017): de identidade indígena; de identidade camponesa; e de identidade proletária rural. Com respeito à unidade da luta latino-americana por eles articulada, identificamos pelo menos quatro eixos de identidade política:

1. Reconfiguração da história e da memória no âmbito das lutas: os movimentos indígenas e camponeses não concebem a história apenas numa perspectiva linear, mas em ciclos em espiral. Pensar a história em ciclos 
permite-lhes, por um lado, interpretar a memória coletiva longa, ${ }^{27}$ determinada por marcos históricos, heranças simbólicas, figuras que expressam a violência colonial permanente sobre os corpos, crenças e conhecimentos desses povos, e, por outro lado, fortalecer memórias coletivas curtas, nas quais se conectam, coexistem e antagonizam com o horizonte colonial. Esta concepção de história, tempo e memória é semelhante ao conceito aimará ñawpaj manpuni, que se refere ao "olhar para trás que também é um ir para a frente" (CUSICANQUI, 1986), ou seja, retomar o passado com uma projeção do futuro que se combina com o presente do processo de resistência política;

2. Dimensões epistêmicas e ontológicas que emanam das cosmovisões e sustentam as bases de uma racionalidade ancestral, que se configura a partir de uma matriz cosmogônica, linguística e sociocultural de carácter milenar. Esta dimensão onto-epistémica sustenta as subjetividades políticas destes movimentos, a sua concepção de tempo, vida e morte, o seu posicionamento (individual e coletivo) no mundo e uma interpretação do ser humano como uma fração da totalidade da vida existente na natureza. Entre as várias referências da matriz onto-epistêmica, cito algumas, por exemplo, o Lekil Kuxlejal, da língua maia, o Sumak Kawsai (do quéchua equatoriano) ou o Sumak Qamaña (do aimará boliviano) ou o bem viver, entendido como princípio essencial dos direitos humanos e da natureza, contrastando com a perspectiva do "viver melhor" defendida pelo capitalismo moderno. Outro exemplo da dimensão epistêmica é a matriz linguística das línguas originais, que determina outras posições de sujeito e pensamento, conferindo horizontalidade entre os indivíduos e a comunidade (LENKERSDORF, 2005).

3. Territorialidade: o território constitui o lugar de re-existência dos povos e de conformação de um ethos, parte constitutiva da narrativa política dos movimentos indígenas e camponeses, na defesa da terra, da natureza e dos bens comuns. O território envolve também os processos de territorialização, um momento de apreensão e construção de identidades para os povos, de modos de ser, de ser e de coexistir. O Tawantinsuyu, o Wallmapu

27 A concepção sociológica de memória que faço uso no escrito é aquela articulada pelo pensamento andino e pelo pensamento maia mesoamericano, a memória longa e a memória curta, a memória em espiral. 
- para citar algumas referências - constituem uma concepção do território como um espaço vivo, numa relação permanente entre o cosmos, as coletividades humanas e não humanas e o ambiente natural em que vivem. Para além de uma perspectiva antropocêntrica, esta relação dá ao território um simbolismo e ritualismo complexo, no reconhecimento da vitalidade do território, dos sentidos de produção, de criação e ressignificação das relações socioculturais e de poder. Com base nisso, o território adquire particular relevância diante dos conflitos inerentes à disputa do capital transnacional através da mineração, do agronegócio, entre outras megaempresas em territórios latino-americanos. Ao interpelar a concepção de território predominante no paradigma moderno ocidental capitalista, os movimentos indígenas e camponeses colocam em movimento ontologias relacionais (ESCOBAR, 2014) e reivindicam o reconhecimento de uma lógica pluriversa de conceber e habitar o território.

4. Autonomia: entendida como princípio e projeto político para muitos movimentos indígenas, é concebida em um vínculo com as dimensões epistêmicas e ontológicas da cosmovisão, do princípio da comunalidade e de um sentimento de pertença territorial preexistente à conformação do EstadoNação como instância institucional, de regulação social e de representação política. Trata-se da reivindicação do direito de autodeterminação dos povos em seus territórios, que faz parte das tradições comunitárias, das formas históricas de deliberação e participação política articuladas pelas comunidades organizadas em torno da vida comunitária em seus territórios, antes da Conquista (TAPIA, 2006; GONZÁLEZ, BURGUETE; ORTÍZ-T, 2010).

Esses quatro eixos traçam a natureza das demandas e a concepção dos projetos políticos conduzidos pelos diferentes povos do campo. Do mesmo modo, têm alimentado as estratégias de luta, entre elas, aquelas relacionadas à perspectiva do patrimônio biocultural e a defesa dos territórios e dos comuns na América Latina. 


\section{Memória e Patrimônio Biocultural na defesa dos territórios e dos comuns}

Os elementos da identidade política apresentados anteriormente demonstram a heterogeneidade dos povos do campo, da natureza de sua luta política e, sobretudo, do paradigma onto-epistêmico que estrutura suas racionalidades e organização da vida social. Um aspecto que interessa destacar é a centralidade desse paradigma na sobrevivência e perpetuação de um patrimônio biocultural, cerne das formas históricas de re-existência e de luta desses povos frente à racionalidade do capitalismo em suas diferentes fases.

Nessa direção, lançarei luzes a um conceito elaborado pela etnoecologia - a memória biocultural - como ferramenta teórico-metodológica que nos permite analisar experiências concretas que sustentam memórias históricas de caráter coletivo e relacionadas à preservação de um patrimônio biocultural, âmago da coexistência da humanidade com a natureza e os não humanos. Na perspectiva da etnoecologia, o processo evolutivo de diversificação biocultural revela uma assemblagem da diversidade da vida humana e não humana nos territórios e representa, em sentido estrito, a própria memória da espécie (TOLEDO; BARRERA-BASSOLS, 2008). Articulada à memória histórica coletiva, comunitária, essa memória biocultural foi, e continua sendo, o elemento histórico que permitiu diferentes grupos humanos permanecerem em determinados lugares por um longo período, por vezes, centenário ou milenário.

Na memória biocultural, a tradição constitui o dispositivo acionado tanto para a manutenção de aprendizagens geracionais como para agregar novas aprendizagens. E embora vivamos um momento histórico de ampla urbanização, industrialização, modernização, tecnificação, persistem em diferentes zonas, comunidades diversas que realizam práticas de produção primária não capitalistas, com o uso prudente dos ecossistemas e dos bens comuns existentes em seus territórios. A combinação entre a memória biocultural e as dimensões epistêmicas e ontológicas que emanam da racionalidade desses povos coloca em movimento sabedorias ancestrais que existem como "consciências históricas comunitárias" que, uma vez conjugadas em sua totalidade, operam como epicentro das recordações 
da espécie, portanto "hipocampo do cérebro da humanidade" que permite sua contínua adaptação a um mundo em permanente mudança (TOLEDO; BARRERA-BASSOLS, 2008).

A memória biocultural é responsável pela preservação de um patrimônio biocultural, que se expressa, por exemplo, na preservação das sementes nativas, nas diferentes formas de manejo natural dos solos, no uso sustentável da água, na recuperação de práticas agroecológicas ancestrais, entre outros conhecimentos que são parte dessa sabedoria ancestral. Ao ser articulada a uma dimensão política da luta em defesa dos territórios e dos comuns, a memória biocultural potencializa as respostas erigidas no campo popular, ao mesmo tempo que aponta horizontes de transformação social em uma perspectiva emancipatória. Do mesmo modo, interpela as contradições inerentes à acumulação por espoliação, como, por exemplo, o fato da agricultura industrial não produzir alimentos e estar baseada no uso intensivo de agrotóxicos, disseminando a contaminação do solo, da água e do ar, além de patologias congênitas e o incremente do câncer nas zonas de predomínio desse modelo de produção agrícola.

Diferentes organizações e movimentos articulam, em escalas local, regional, nacional e transnacional, projetos políticos com forte raiz na memória biocultural e avançam na defesa dos territórios e dos comuns. Exemplares são a Via Campesina e a Coordenadora Latino-Americana de Organizações do Campo - CLOC, movimentos de caráter transnacional que reúnem uma diversidade de organizações nos diferentes continentes em defesa da agroecologia, da soberania alimentar, nos direitos dos camponeses e demais povos do campo (BARBOSA; ROSSET, 2017). Do mesmo modo a luta política do Movimento Zapatista no México e diferentes movimentos indígenas vinculados à Coordenação Continental das Nacionalidades e Povos Indígenas do Abya Yala, em sua crítica radical ao paradigma ocidental moderno capitalista. Em cada país da região, em suas diferentes regiões, encontraremos exemplos que validam a existência dessa memória biocultural e de como se articula ao patrimônio biocultural. 


\section{Considerações finais}

No presente capítulo teci algumas considerações em torno à existência de uma disputa histórica entre paradigmas - o paradigma onto-epistêmico do campo e o paradigma ocidental moderno capitalista — que são parte de uma disputa territorial entre o capital e os povos do campo na América Latina.

Para tanto, sustento que a própria existência de outras ontologias e epistemologias entre esses povos revela a permanência histórica de formas de organização sociocultural das sociedades não capitalistas que sobreviveram ao despojo violento e permanente do continuum da reprodução ampliada do capital, processo corrente durante a modernidade. Nesse sentido, a memória biocultural emerge como um conceito que deveria ser apropriado sociologicamente, como um dispositivo fundamental à garantia da preservação do patrimônio biocultural, compreendendo-o como cerne da coexistência da humanidade em intrínseca relação com a natureza.

É sabido que o escrito não aprofunda a análise em experiências concretas que demonstram a relação entre memória biocultural e formas efetivas de defesa dos territórios e dos comuns. Entretanto o intuito é o de abrir essa reflexão como uma possibilidade de pesquisa não só no campo dos estudos agrários e da sociologia rural, mas para todo o campo sociológico que se propõe a pensar as dialéticas e contradições inerentes à modernidade e ao próprio surgimento do capitalismo como sistema-mundo. Também para colocar em perspectiva crítica categorias adjetivadas comumente usadas em estudos sociológicos, a propósito do "atrasado", "primitivo", "aborígenes", entre outras, que nascem da abordagem colonial e capitalistas em relação às sociedades não capitalistas. 



\section{REFERÊNCIAS}

ALBÓ, X.; BARRIOS, R. Violencias encubiertas en Bolivia. La Paz: CIPCA, 1993.

BARBOSA, L. P. Paradigma epistémico do campo e a construção do conhecimento na perspectiva dos movimentos indígenas e camponeses da América Latina. In: SANTOS, A. R. et. al. Educação e movimentos sociais: análises e discursos. Jundiaí: Paco Editorial, 2019a. p. 279-299.

BARBOSA, L. P. O Popol Wuj na contemporânea luta indígena mesoamericana. Tensões Mundiais, v. 15, n. 28, p. 75-102, 2019b. BARBOSA, L. P. Dilemmas of peasant social movements faced with the dichotomy between progressive governments and the rise of the new right in Latin America: the case of Brazil. INTERNATIONAL CONFERENCE AUTHORITARIAN POPULISM AND RURAL WORD, 2018, [S.l., Netherlands]. Proceedings [...]. [S.l., Netherlands]: International Institute of Social Studies (ISS), 2018.

BARBOSA, L. P. Brasil. La disputa de proyectos políticos en el siglo XXI. In: OLIVER, L. (Coord.) Transformaciones recientes del Estado Integral en América Latina: críticas y aproximaciones desde la sociología política de Antonio Gramsci. México: UNAM, 2016. p. 185-209.

BARBOSA, L. P.; ROSSET, P. M. Educação do campo e pedagogia camponesa agroecológica na América Latina: aportes da la via campesina e da CLOC. Educação \& Sociedade, v. 38, n. 140, p. 705-724, 2017. 
BARRERA-VÁZQUÉZ, A.; RENDÓN, S. El libro de los libros de

Chilam Balam. México: Fondo de Cultura Económica, 2012.

CUSICANQUI, S. R. Sociología de la imagen: miradas ch'ixi desde la historia andina. Buenos Aires: Tinta Lemón, 2015.

CUSICANQUI, S. R. Oprimidos pero no vencidos.

Bolívia: Hisbol, 1986.

DE LA GARZA, M. El Legado escrito de los Mayas. México: Fondo de Cultura Económica, 2012.

ESCOBAR, A. Sentipensar con la tierra: nuevas lecturas sobre desarrollo, territorio y diferencia. Medellín: Editora UNAULA, 2014.

FEDERICI, S. O Ponto zero da revolução: trabalho doméstico, reprodução e luta feminista. São Paulo: Elefante, 2019.

FRIEDRICH, E. Sobre o papel do trabalho na transformação do macaco em homem. [S.1.]: Ridendo Castigat Mores, 1999. Disponível em: http://www.ebooksbrasil.org/adobeebook/macaco.pdf. Acesso em: 31 mar. 2020.

GIACARRA, N. Territorios en disputa: los bienes naturales en el centro de la escena. Realidad Económica, n. 217, p. 51-68, 2006.

GONZÁLEZ, M.; BURGUETE, A.; ORTIZ-T, P. La autonomía a debate: autogobierno indígena y estado plurinacional en América Latina.

México: CIESAS/UNICH, 2010.

LENKERSDORF, C. Los hombres verdadeiros: Voces y testimonios tojolabales. México: Siglo XXI, 2005.

LUXEMBURGO, R. A acumulação do capital: estudo sobre a interpretação econômica do Imperialismo. Rio de Janeiro: Zahar, 1970. MARIÁTEGUI, J. C. Siete ensayos de interpretación de la realidad peruana. México: ERA, 1928.

MARX, K. O Capital: livro 1. São Paulo: Boitempo, 2011. 
OSORIO, J. América Latina: o novo padrão exportador de especialização produtiva. In: PALLEY, T. (Org.). Financialization: what it is and why it matters. Washington DC: The Levy Economics Institute and Economics for Democratic and Open Societies, 2007. (Working Paper, n. 525).

SVAMPA, M.; ANTONELLI, M. Minería transnacional, narrativas del desarrollo y resistencias sociales. Buenos Aires: Biblos, 2009. TAPIA MEALLA, L. La Invención del núcleo común. Ciudadanía y gobierno multisocietal. La Paz: Muela del Diablo Editores, 2006. (Colección Postgrado en Ciencias del Desarrollo-CIDES/UMSA).

TOLEDO, V. M.; BARRERA-BASSOLS, N. La Memoria biocultural: la importancia ecológica de las sabidurías tradicionales. Barcelona: Icaria Editorial, 2008.

\section{VAN DER PLOEG, J. D. Camponeses e impérios alimentares:}

lutas por autonomía e sustentabilidade na era da globalização. Porto Alegre: UFRGS, 2008.

VELTMEYER, H. Resistance, class struggle and social movements in Latin America: contemporary dynamics. The Journal of Peasant Studies, v. 46, n. 6, p. 1264-1285, 2019, 